I would therefore ask those interested in pneumothurax work, and in the idea of forming an association, to communicate with me.

H. Schwatt, M.D., Edgewater, Colo.

Superintendent, Sanatorium of the Jewish Consumptives' Relief Society.

\section{Cooperatively Conducted Local Hospitals}

To the Editor:-I have learned that in a number of localities the physicians of small country towns have joined together and conducted a successful hospital for the community. Please give me plans or methods of undertaking the establishment of a hospital of the kind in a county seat town of about 2,000 inhabitants, by-laws governing the physicians interested, etc. Please give me the addresses of physicians who have adopted such methods of work and all the information you can to get a movement of this kind started in our community.

M. P. O.

[CommLnt.-We shall be glad to receive information regarding the proposition, either for publication or to be forwarded to the writer of the letter.-Ev.]

\section{Queries and Minor Notes}

Anonymovs communications and queries on postal cards will no be noticed. Every letter must contain the writer's name and address, but these will be omitted, on request.

\section{TOOTH DETERGENTS}

To the Editor:- - Has TIIE Jouknal published any report on the deterTont and antiseptic effects of the various preparations advertised for cleansing the teeth? If not, would it not be well in the interest of many readers who must wish accturate information on the selection of an effective agent to have the Council examine and report on this question?

S. T. A.

Answer,-The Journal has published recently in the Department of Therapeutics (Nov. 8 and 15, 1913, pp. 1719 and 1812) an article on oral cleanliness which discusses the principles involved in the use of tooth-powders and other preparations for cleansing the teeth. One of the constituents of many tooth-powders is soap, and this ought to be a harmless substance except for the objection to its alkalinity. The reason for employing an alkaline substance seems to be that it is recognized that dental decay is due to the effect of acids formed by fermentation. These acids, however, do not accumulate on the teeth in the free state but unite with the lime-salts of the enamel or dentine as soon as they are formed. The alkalinity of the ordinary toothpowder can be of little service because its occasional application can do nothing to check the action of acids which are continuously formed during the intervals. Moreover, the use of an alkaline application to the teeth may be a positive detriment by depressing the secretion and alkalinity of the saliva on the principle that a secretion which is no longer needed ceases to be formed. Pickerill ("Stomatology in General Practice," p. 100) has shown that alkalies applied to the teeth and gums reduce both the amount and alkalinity of the saliva secreted subsequently to the application of the alkali, while the reverse effect is produced by acids. Hence he recommends a weakly acid application rather than the alkali. Another reason for the use of acid has been advanced by W. J. Gies (Household Arts Reviezu, May, 1913, p. 12; The Journal, Nov. 8, 1913, p. 1719), who found that alkaline applications did not readily dissolve the mucus which retained the fermenting food on the teeth and hence were not efficient cleansers. He also advocates the substitution of acid solutions. Pickerill has found that daily rubbing the teeth with a weak solution of tartaric acid did not remove any appreciable amount of the material of the tooth. It seems, therefore, that tooth detergents should be made of weak acids rather than weak alkalies.

An antiseptic is usually added to these preparations with a view to hindering the proliferation of the numerous microorganisms whicl, are found in the mouth or introduced with the food. It is time that physicians should have clear ideas as to what can be expected from antiseptics applied to the oral cavity. To disinfect the mouth would be a difficult matter, and in practice is not worth attempting, unless by the direct work of a skilful operator. To give the patient an antiseptic with which to treat the mouth is worse than useless. If the object is to prevent putrefaction or fermentation it is much simpler to remove mechanically the fermentable material than to attempt to preserve it with an antiseptic. Pickerill suggests that not only is an antiseptic which is in contact with the organisms not more than three minutes a day of no use, but not improbably it has the reverse effect-that of producing a more vigorous and resisting strain of organisms due to the slight and intermittent opfosition to their growth and to the survival of the fittest. This author states that for a chronic and slowly progressing lesion like caries of the teeth, the intermittent use of antiseptics is of no value. Their use should be limited to acute conditions and then they should be used frequently and in full strength, that is, as strong as can be tolerated, with the object of rapidly reducing the number and virulence of the organisms.

\section{OPERATING-ROOM SLUMBER SONGS}

To the Editor:-In your issue of June 6, I read with interest Dr. Kane's account of his musical operating-room. No doubt it is an admirable way of assisting the anesthetist, although I can imagine some of the disadvantages. For example, a patient given to dancing might become uncontrollable on hearing the "Arentine to dancing then, again, the surgical nurse night be the cause of complications were one to play the "Matrimonial Glide." But outside of these unforewere one to play the "Matrimonial Glide." But outside of
seen accidents good results could no doubt be obtained.

As a historical note I would add that Dr. Kane is not a pioneer in
Anten accidents good results could no doubt be obtained.

this respect. Henri de Mondeville (1260-1320), a shining light in his time and possissed of a most delightful line of sarcasm, advocated the following:

"Keep up your patient's spirits by music of viols and ten-stringed psaltry, or by telling him that he has been elected to a bishouric if church man, or by forged letters telling him of the deatli of his church nemies."

R. W. Mendrison, M.D., Des Moines, liwa.

ANSWER.-Apropos of this we quote the following stiggestio:s from B. L. T.'s Line-O'-Type Department of the (hicago Tribune:

SELECT YOUR RECORD [June 8]

"I owe to Dr. Burdick, our anesthetist, thanks for his selection of records admirably adapted to the tastes and temperament of the suthjects." - Evan O'Neil Kane, M.D., Kane, Pa.

This opens up a new avenue of fancy. When you are laid on the table and the saw is called for, what would be your choice of phono-
graph records? M. F. votes for "This is the Life."

TIE ANESTHESIEST WAY [June 10]

Select your phonograph record before you go "under the knife."

("hick: "You can put me down for 'Good-Bye, Everybody,"

L. C. W.: "If You Talk in Your Sleep, Don't Mention My Name."

TIIE ANESTIIESIEST WAY [June 12

When I am on the table

And the surgeon's saw I see,

"What Will start the record,

I Jandy: "Just Tell Them that You Saw Me,"

- Martia.

W. M. B.; "Any hymn found in the appendix-to be followed by the anesthesiest way [June 15]

C. E. B.: Turn on the record, "How happy could I be with Ether were t'other dear charmer away"

P. B. D.: "I Don't Know where I'm Going, But I'm on My W'ay."

F. C. F.: "Good Night, Nurse"

if. I. P.: "She Sleeps in the Deep."

THE ANESTIIESIEST WAY |J UMe $20 \mid$

Prize record, besought by H. M.: "Let a little sunshine in."

ARTICLES ON INTESTINAL OBSTRCCYION DLE TO WIRMS

To the Editor:-Kindly refer me to any literature on the subject of ascariasis.

H. Robenstein, M.D., Chicaro.

Answer.-The following is a list of articles on the subject:

Van Meter, B. F.: Intestinal Obstruction Due to Roundworms, Surg. Gynec, and Obst., April, 1909

Venning, R. E.: Intestinal Obstruction from Ascarides Lumbricoides, The Journal, June 18, 1910 , p. 2041 .

Whelan, Charles: Intestinal Obstruction Due to Ascarides Lumbri coides, with Autopsy, THE Journal, Oct. 22, 1910, p. 1442.

Roll, J.: Oxyuris as a Cause of lleus, Norsk. Mag. f. Laegeridensk., 